\title{
PRODUÇÃO EXTEMPORÂNEA DA VIDEIRA, CULTIVAR SYRAH, NAS CONDIÇÕES DO SUL DE MINAS GERAIS ${ }^{1}$
}

\author{
DANIEL ANGELUCCI DE AMORIM², ANA CAROLINA FAVERO³, MURILLO DE ALBUQUERQUE REGINA ${ }^{4}$
}

\begin{abstract}
RESUMO - Avaliou-se a produção extemporânea da videira, através de uma segunda poda anual, nas condições climáticas do sul de Minas Gerais. O experimento foi conduzido em vinhedo não-irrigado, da cultivar Syrah, clone 747 ENTAV-INRA, enxertada sobre o '3309 C' e conduzido no sistema de espaldeira, com espaçamento de 2,50 x 1,50 metros. A primeira poda de formação das plantas foi realizada em agosto de 2002, enquanto a poda de produção foi realizada no mês de janeiro, em ramos totalmente lignificados. O ciclo completo de produção foi de 164 dias e a precipitação pluviométrica acumulada neste período, de $480 \mathrm{~mm}$, sendo que, nos últimos 15 dias que antecederam a colheita, não foi registrada nenhuma precipitação. Os valores do potencial hídrico de base permaneceram bastante baixos (valores absolutos) durante todo o ciclo, ao mesmo tempo que a transpiração das folhas e a assimilação do carbono se mantiveram em níveis elevados, caracterizando a ausência de estresse hídrico durante o ciclo de produção. A produção atingiu 8,45 t.ha- ${ }^{-1}$ com $21,75^{\circ}$ brix e 100 Meq.1.1 de acidez total na colheita, permitindo concluir que, nas condições de estudo, é possível a obtenção de um ciclo de outono para a videira com bons índices de produção sem o emprego da irrigação.
\end{abstract}

Termos para Indexação: poda, alimentação hídrica, trocas gasosas, Vitis vinifera.

\section{EXTEMPORANEOUS PRODUCTION OF VINES, CULTIVAR SYRAH, IN THE CONDITIONS OF THE SOUTH OF MINAS GERAIS}

\begin{abstract}
The extemporaneous production of vines was evaluated, through a second annual prune, in the climatic conditions of the South of Minas Gerais. The experiment was carried out in a non irrigated vineyard, of the cultivar Syrah, clone 747 ENTAV-INRA, grafted on 3309 C and conducted in the vertical system, with spacing of 2,50 x 1,50 meters. The first pruning of plant's formation was accomplished in August of 2002, while the production pruning was in the month of January in branches completely lignified. The complete cycle of production was of 164 days and the precipitation accumulated in this period was $480 \mathrm{~mm}$, being that wasn't registered any precipitation on the last 15 days before the harvest. The values of the water potential stayed low (absolute mark) during the whole cycle, at the same time that, the transpiration of the leaves and the assimilation of the carbon stayed in high levels, characterizing the absence of water stress during the production cycle. The production reached 8,45

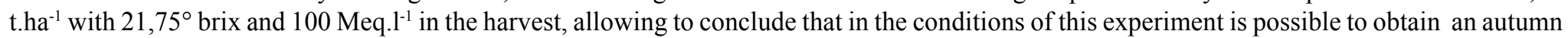
cycle for the vine with good production rates, without the employment of the irrigation.
\end{abstract}

Index terms: pruning, water supply, gas exchange, Vitis vinifera

A qualidade dos vinhos finos nacionais tem passado por constantes evoluções nos últimos anos, incorporando notáveis melhorias, principalmente no que diz respeito ao emprego de cultivares finas e às técnicas enológicas. Tal condição permite classificá-los no quarto período de sua escala evolutiva, onde se busca a afirmação da identidade regional (Tonietto, 2002). O principal desafio para a continuidade desta evolução qualitativa é a melhoria da qualidade da uva, pois é sabido que as condições climáticas verificadas durante o período de maturação da uva das principais regiões vitícolas brasileiras, várias vezes, não permitem a obtenção de ótimo estado de maturação, quer seja pelo excesso de precipitações pluviométricas, comum nos Estados do Sul (exceção feita aos anos de seca nas regiões vitícolas gaúchas), quer seja pela falta da amplitude térmica entre dia e noite que ocorre nas regiões tropicais. Neste sentido, várias iniciativas têm sido tomadas atualmente no Brasil, com o propósito de identificar novas regiões vitícolas, onde as condições ecológicas sejam mais favoráveis à obtenção de melhores índices de maturação e qualidade da uva. Buscase a identificação de regiões onde ocorram menores índices de precipitação pluviométrica no período que antecede a colheita, associados a uma amplitude térmica que permita uma síntese de açúcares aliada ao decréscimo da acidez e aumento dos teores de polifenóis (Guerra, 2002; Champagnol, 1984; Huglin, 1986). Em Minas Gerais, na tradicional zona vitícola da região sul, a videira inicia sua brotação em setembro, floresce em outubro e inicia sua maturação em dezembro para ser colhida entre meados de janeiro e meados de fevereiro (Souza et al., 2002), período em que os índices de precipitação pluviométrica mensal ultrapassam facilmente os 200 milímetros, condição que não permite uma boa maturação das uvas, além de torná-las bastante suscetíveis à ocorrência de diversas formas de podridões. Por outro lado, verifica-se em grande parte dos Estados da região Sudeste brasileira, que as chuvas de verão se encerram no final de março, dando início a um período de outono/inverno seco e com temperaturas amenas, condição que, a princípio, poderia prestar-se à obtenção de uvas com bons índices de maturação. Esse é o caso do município de Três Corações, situado na região cafeeira do sul de Minas Gerais, a uma altitude média de 900 metros, onde as condições climáticas predominantes são caracterizadas pela ocorrência de verão chuvoso, seguido de outono e inverno secos e amenos. A precipitação pluviométrica média anual totaliza $1.300 \mathrm{~mm}$, sendo que a maior intensidade de chuvas se estende de final de setembro a final de março. Durante os meses de abril a setembro, a precipitação atinge valores totais médios de $190 \mathrm{~mm} / \mathrm{mês}$, limitando-se a uma média de 22,5 milímetros mensais no período compreendido entre maio e agosto (EPAMIG, 1982). A temperatura média anual do ar desta região é de $19^{\circ} \mathrm{C}$, com as menores temperaturas nos meses de maio a julho. Nesse mesmo período, a diferença entre as temperaturas máxima e mínima do ar alcança $11 ; 15$ e $15^{\circ} \mathrm{C}$ para os meses de maio, junho e julho, respectivamente (EPAMIG, 1982), e a temperatura média do ar situa-se entre 16 e $17^{\circ} \mathrm{C}$. Pelo exposto, pode-se concluir que a época mais indicada para a colheita seria a dos meses de outono e inverno, de forma a evitar os excessos de chuvas do verão. Aliás, esta prática já é adotada pelos produtores de uva de mesa do vale do São Francisco, igualmente situado em área tropical, que conseguem, através do uso da irrigação artificial e do manejo de poda e aplicação de reguladores de crescimento, alterar a colheita para os meses mais secos do ano, de forma a garantir melhores preços e menores ataques de doenças fúngicas (Albuquerque et al., 1996; Leão, 2001; Leão \& Maia, 1998).

Neste sentido, este trabalho teve como objetivo verificar a possibilidade de se imprimir um segundo ciclo anual vegetativo e produtivo da videira, nas condições climáticas do sul de Minas Gerais, sem o uso de irrigação e através da poda e quebra de dormência artificial

\footnotetext{
${ }^{1}$ (Trabalho 002/2005). Recebido: 05/01/2005. Aceito para publicação: 13/07/2005. Trabalho financiado pela FAPEMIG.

${ }^{2}$ Eng. Agr. MsC., EPAMIG, Fazenda Experimental de Caldas, Caixa Postal 33, CEP 37780-000 Caldas, MG. E-mail: daniel@epamigcaldas.gov.br.

${ }^{3}$ Eng. Agr., BsC., EPAMIG, Mestrando DAG/UFLA. E-mail: anacarolina@epamigcaldas.gov.br.

${ }^{4}$ Eng. Agr. DsC., EPAMIG, Fazenda Experimental de Caldas, Caixa Postal 33, CEP 37780-000 Caldas, MG. Bolsista CNPq. E-mail: murillo@epamigcaldas.gov.br.
} 
das gemas, para alterar o período de colheita para os meses mais secos do ano, buscando a melhoria do índice de maturação de uvas destinadas à elaboração de vinhos finos.

Este projeto foi executado em propriedade particular, denominada Fazenda da Fé, situada no município de Três Corações, região sul do Estado de Minas Gerais, localizado a 900 metros de altitude, $21^{\circ}$ de Latitude $\mathrm{S}$ e $45^{\circ}$ de Longitude $\mathrm{W}$.

Foi empregado um vinhedo experimental de 300 plantas, nãoirrigado, com espaçamento de 2,50 x 1,50 metros, instalado em agosto de 2001, com mudas da cultivar Syrah, clone 747 do ENTAV-INRA ${ }^{\circledR}$, selecionado como de produtividade intermediária (ENTAV, 1995), enxertadas sobre o porta-enxerto $3309 \mathrm{C}$, provenientes da França e fornecidas pela empresa Vitplant ${ }^{\circledR}$. As plantas foram conduzidas em espaldeira e podadas em duplo cordão esporonado.

Em agosto de 2002, realizou-se uma primeira poda para a formação dos ramos, em esporão de duas gemas, tendo sido eliminada toda a produção originada dos ramos brotados. Em 18 de janeiro de 2003, após a lignificação completa dos ramos, efetuou-se a poda de produção com varas de 8 gemas, que foram arqueadas à altura do primeiro fio de arame da espaldeira, deixando-se aproximadamente 24 gemas por planta. Logo em seguida, aplicou-se cianamida hidrogenada (Dormex ${ }^{\circledR}$ ) por pincelamento direto das gemas, na dosagem de $6,0 \%$ do produto comercial.

Para fins de avaliação das diversas variáveis agronômicas, como \% de brotação, estádios fenológicos e produção, foram selecionadas 24 plantas aleatoriamente no vinhedo, guardando-se, entretanto, um padrão de uniformidade de vigor entre elas. Realizou-se a contagem das gemas após a poda, e de gemas brotadas. Avaliou-se também a fertilidade dos ramos por contagem direta do número de ramos e cachos por planta.

Os registros fenológicos de brotação, floração e maturação foram efetuados adotando-se os critérios definidos por Carbonneau (1981). O início da maturação (ou início do pintor) foi considerado quando pelo menos duas bagas em cachos diferentes já haviam mudado de cor, enquanto o final da maturação, quando apenas dois cachos por planta ainda não apresentavam todas as bagas viradas. A produção foi avaliada por contagem e pesagem do número de cachos por planta das 24 plantas selecionadas. Os dados climáticos de precipitação pluviométrica diária foram coletados através de pluviômetro instalado na propriedade e nas proximidades da parcela experimental.

O potencial hídrico de base foi avaliado com uma câmara de pressão tipo Scholander (modelo Soilmoisture), empregando o nitrogênio como gás inerte. As avaliações foram realizadas nos mesmos dias das avaliações das trocas gasosas, entre $04 \mathrm{~h} 30$ e $05 \mathrm{~h} 30$, sempre antes do nascer do sol. Em cada série de avaliações, foram amostradas 13 folhas adultas retiradas da porção mediana de ramos produtivos.

As trocas gasosas das folhas foram avaliadas a partir do estádio de floração através de analisador portátil de $\mathrm{CO}_{2}$ por infravermelho (modelo Cid 301 PS), trabalhando em circuito aberto. As medições foram feitas sempre no período da manhã, entre $9 \mathrm{~h}$ e $11 \mathrm{~h}$, em condição de luminosidade saturante (superior a $1.000 \mu \mathrm{mol} \cdot \mathrm{m}^{-2} \cdot \mathrm{s}^{-1}$ ). Em cada série de medições, foram amostradas 30 folhas adultas, sadias e situadas na porção de ramos produtivos.

A evolução da maturação foi acompanhada através de amostragens semanais de 200 bagas retiradas aleatoriamente no vinhedo, a partir do final do estágio fenológico de pintor, ou mudança de cor das bagas. Avaliaram-se o brix por refratometria e a acidez por titulação em $\mathrm{NaOH}$

A brotação das gemas ocorreu no décimo segundo dia após a poda, seguindo-se da floração ao trigésimo sexto dia, frutificação das bagas no quadragésimo quarto, início da maturação no octogésimo sétimo, totalizando um ciclo de 164 dias entre a poda e a colheita (Tabela 1). Este ciclo foi superior aos 154 dias observados para a mesma cultivar no verão, em Caldas (Souza et al., 2002), e inferior aos 193 dias verificados para a cultivar Syrah, na Austrália, por Ginestar et al. (1998). Entretanto, ao considerar somente o período de maturação, constatouse um prazo de 76 dias entre o início da maturação (pintor) e a colheita, tempo superior aos 74 dias observados por Ginestar et al. (1998) para as condições australianas. Guerra (2002) cita que o período de maturação das uvas varia de 40 a 50 dias, em função da cultivar e da região de cultivo. A extensão deste período, verificada neste caso, pode ser atribuída às temperaturas mais baixas ocorridas durante outono e início do inverno e, em princípio, podem representar um aspecto positivo para a qualidade da uva, permitindo uma lenta evolução dos componentes da maturação, ou até mesmo uma sobrematuração das bagas.

Durante todo o ciclo da videira, foram registrados $480 \mathrm{~mm}$ de chuva (Tabela 2), dos quais $403 \mathrm{~mm}$, ou seja, 83,9\%, durante as fases de brotação e início de maturação. Willians \& Matheus (1990) e Doorenbos \& Kassam (1979), citados por Pires et al. (2003), afirmam que a necessidade de água durante o ciclo da videira varia de 500 a $1.200 \mathrm{~mm}$, dependendo do clima e da duração do período de crescimento. Nesse caso, se considerarmos que a brotação da videira ocorreu em 30 de janeiro, e que as chuvas que antecederam esse período durante o mês de janeiro atingiram $464 \mathrm{~mm}$, o que totalizaria $944 \mathrm{~mm}$ entre início de janeiro e final de junho, podemos concluir que o volume total de precipitação acumulado durante todo o ciclo é suficiente para atender às necessidades da videira, dispensando, a princípio, o uso da irrigação. Por outro lado, ao analisarmos a precipitação acumulada durante o período de maturação, pôde-se observar que ela se restringiu a $77 \mathrm{~mm}$ entre o início da maturação e a colheita, com apenas $55 \mathrm{~mm}$ a partir do fim da mudança de cor das bagas. Para as condições australianas, Ginestar et al. (1998) verificaram $35 \mathrm{~mm}$ neste mesmo período. No presente trabalho, registrou-se que, nos 53 dias que antecederam a colheita, as chuvas se limitaram a $3 \mathrm{~mm}$, e que não ocorreram quaisquer chuvas nos últimos 15 dias que anteciparam a colheita.

Os valores do potencial hídrico de base até o octogésimo sétimo dia após a poda, correspondendo ao estado fenológico de início de maturação dos cachos, permaneceram baixos e vizinhos a - $0,2 \mathrm{MPa}$

TABELA 1 - Registros fenológicos de brotação, floração, frutificação, maturação e colheita da videira/cv. Syrah, em ciclo de outono. Três CoraçõesMG.,2003.

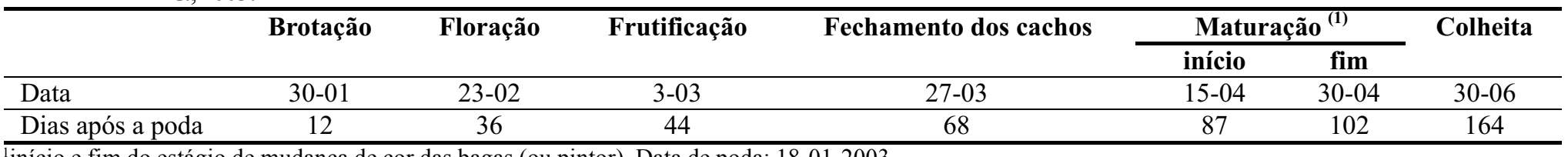

início e fim do estágio de mudança de cor das bagas (ou pintor). Data de poda: 18-01-2003.

TABELA 2 - Precipitação pluviométrica registrada durante o ciclo de outono da videira/cv. Syrah. Três Corações-MG, 2003.

\begin{tabular}{|c|c|c|c|c|c|c|c|}
\hline & \multicolumn{7}{|c|}{ Precipitação pluviométrica acumulada no subperíodo fenológico (mm) } \\
\hline & \multirow[t]{2}{*}{ Brotação } & \multirow[t]{2}{*}{ Floração } & \multirow[t]{2}{*}{ Frutificação } & \multirow[t]{2}{*}{ Fechamento dos cachos } & \multicolumn{2}{|c|}{ Maturação } & \multirow[t]{2}{*}{ Colheita } \\
\hline & & & & & Início & Fim & \\
\hline Data & $(30 / 01)$ & $(23 / 02)$ & $(3 / 03)$ & $(27 / 03)$ & $(15 / 04)$ & $(30 / 04)$ & $(30 / 06)$ \\
\hline Chuva (mm) & 181 & 73 & 44 & 105 & 22 & 0 & 55 \\
\hline
\end{tabular}

Data de poda: 18-01-2003 
(figura 1 A). Em seguida, observou-se uma redução considerável até os -0,5 MPa no centésimo segundo dia, redução esta explicada pela estiagem verificada no mesmo período. Esse valor, entretanto, encontrou-se abaixo do indicativo de situação de estresse hídrico para a videira, o que pode ser comprovado pelos valores de transpiração (figura 1 B) e fotossíntese (figura $1 \mathrm{C}$ ) que praticamente não se alteraram no mesmo período. A partir do centésimo décimo dia após a poda, verificou uma redução dos valores do potencial hídrico de base, para se estabelecer em torno de $0,25 \mathrm{MPa}$ até o final do ciclo, mesmo com ausência de chuvas nesse período. Tal situação pode ser explicada pela redução da evapotranspiração devida à redução da temperatura e diminuição do fotoperíodo, e também pela própria redução da área foliar das plantas, que, ao final do ciclo, já demonstravam sinais de senescência. Mesmo assim, observou-se a manutenção de índices consideráveis das trocas gasosas foliares até o momento da colheita.

A atividade fotossintética das folhas, que alcançou o ponto máximo de $11,5 \mu \mathrm{mol} \mathrm{CO} \cdot \mathrm{m}^{-2} \cdot \mathrm{s}^{-1}$ no início da maturação, reduziu-se lenta e progressivamente até o final do ciclo, situando-se na faixa de 7,0 a 8,0
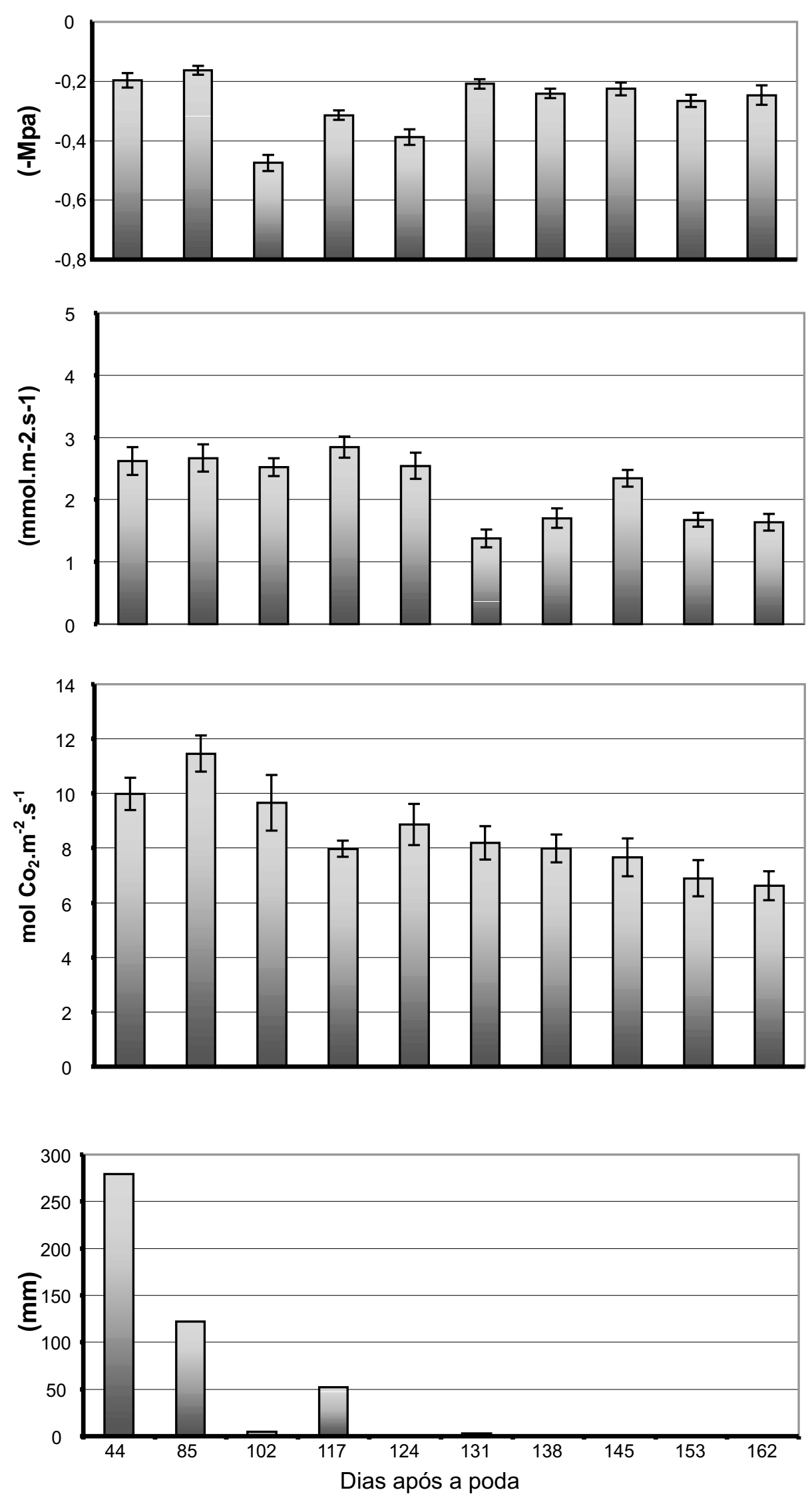

FIGURA 1 - Potencial Hídrico (A), conductância estomática (B), atividade fotossintética (C) e precipitação pluviométrica (D) durante o ciclo de outono da videira, cv Syrah. Três Corações-MG, 2003. 
umol $\mathrm{CO}_{2} \cdot \mathrm{m}^{-2} \cdot \mathrm{s}^{-1}$, valores que podem ser considerados como bastante satisfatórios para a videira, conforme observado na Alemanha (Alleweldt e Ruhl, 1982; During, 1988 e 1992), Austrália (Downtown et al., 1987) e Portugal (Chaves, 1986; Castro et al., 1993).

Da mesma forma, a transpiração das folhas manteve-se em valores praticamente estáveis e próximos a $3,5 \mathrm{mmol} \cdot \mathrm{m}^{-2} \cdot \mathrm{s}^{-1}$ até o centésimo vigésimo quarto dia após a poda, para, em seguida, oscilarse com tendência à redução a valores inferiores a $2 \mathrm{mmol} \cdot \mathrm{m}^{-2} \cdot \mathrm{s}^{-1}$. Em seu contexto geral, estas observações permitem supor que, apesar da estiagem prolongada verificada a partir do início da maturação, as reservas hídricas do solo permitiram a manutenção de um bom estado de hidratação das plantas, capazes de assegurar a manutenção de taxas de transpiração e de assimilação do carbono indispensáveis à maturação dos frutos.

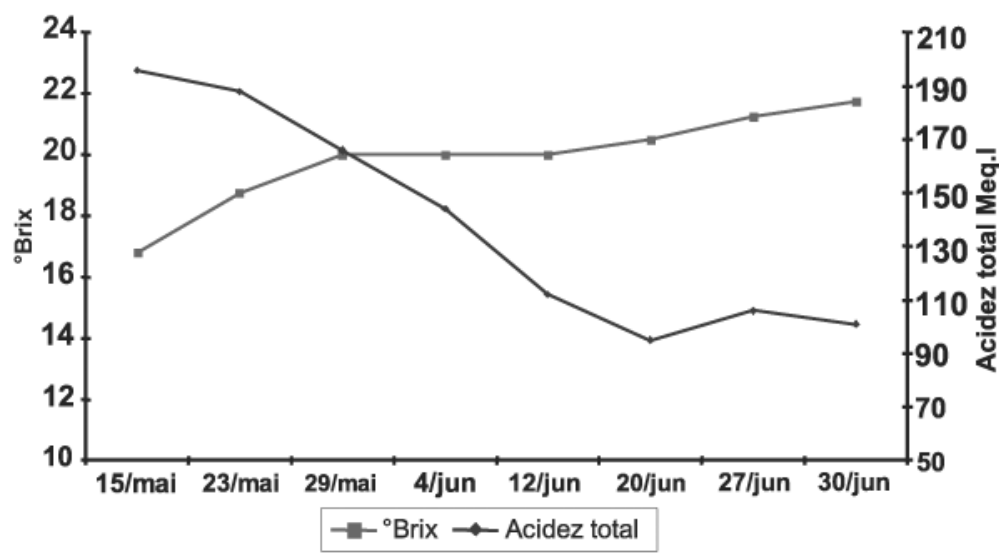

FIGURA 2 - Evolução da maturação das uvas, cv. Syrah, durante o ciclo de outono. Três Corações-MG, 2003

Efetivamente, ao analisar a evolução da maturação das bagas (Figura 2), pôde-se observar que os teores dos sólidos solúveis aumentaram de 16,8 para $20^{\circ}$ Brix entre o centésimo décimo sétimo e o centésimo trigésimo primeiro dia após a poda, para, em seguida, manterem-se estáveis até o centésimo qüinquagésimo terceiro dia. Nos últimos quinze dias que antecederam a colheita, verificou-se ainda um aumento do teor de sólidos solúveis para $21,75^{\circ}$ Brix, elevação esta provavelmente devida à concentração dos açúcares por desidratação das bagas.

No mesmo período, a evolução da acidez total das bagas revelou reduções constantes, do início do período observado até o centésimo qüinquagésimo terceiro dia após a poda (figura 2), para estabelecer-se em torno dos 100 Meq. $\mathrm{l}^{-1}$, com uma ligeira tendência de acréscimo nos últimos quinze dias que antecederam a colheita, fato que corrobora afirmativa de desidratação das bagas.

Os índices de maturação alcançados neste trabalho podem ser considerados satisfatórios se comparados aos valores médios de $17^{\circ} \mathrm{Brix}$ e 125 Meq..$^{-1}$, em quatro safras, relatados por Souza et al. (2002) para a mesma cultivar em safra de verão, no sul de Minas Gerais, e aos $23^{\circ}$ Brix obtidos por Ginestar et al. (1998), na Austrália. Há de se considerar ainda que os dados expressos neste trabalho refletem os valores obtidos com plantas de dois anos em sua primeira produção.

Nas 24 plantas úteis avaliadas, o número médio de gemas deixadas por ocasião da poda foi de 26,7 , sendo que $48 \%$ delas brotaram após aplicação da cianamida hidrogenada (Tabela 3 ). O número médio de cachos por planta foi de 19,83, o que se traduziu em uma fertilidade média de 1,56 cacho por ramo. Por ocasião da colheita, o peso médio dos cachos alcançou 160 gramas, levando a uma produção média de 3,17 kg.planta ${ }^{-1}$, ou seja, de 8,45 t.ha ${ }^{-1}$, se considerarmos a densidade de 2.666 plantas.ha ${ }^{-1}$ empregadas neste ensaio.

As informações preliminares deste estudo permitem afirmar que é possível a obtenção de um ciclo vegetativo e produtivo da videira durante o outono a partir de uma poda de frutificação realizada em ramos lignificados durante o mês de janeiro. O principal interesse desta técnica reside no fato de que o período de maturação das uvas no ciclo de outono oferece condições climáticas mais favoráveis à obtenção de uvas de qualidade para vinificação, notadamente pela escassez de chuvas e amplitude térmica entre dia e noite. Por outro lado, a intensidade pluviométrica incidente no verão, e antes do ciclo de produção, possibilita, através de um bom acúmulo de água no solo, a expressão de um novo ciclo vegetativo e produtivo sem o emprego da irrigação, o que pode ser bastante vantajoso, em termos de redução dos custos de instalação do vinhedo. Evidentemente, estes estudos ainda devem ser prosseguidos e completados por outros, notadamente no tocante ao comportamento de outras cultivares e porta-enxertos e, posteriormente, de evolução da maturação e condução da vinificação, visando a validar o potencial desta região para elaboração de vinhos finos, empregando o manejo proposto.

Os autores agradecem à FAPEMIG, Fazenda da Fé e as empresas Vitiplant ${ }^{\circledR}$ e Vitácea Brasil, pela colaboração prestada ao desenvolvimento do trabalho.

TABELA 3 - Percentual de gemas brotadas, índice de fertilidade dos ramos e produção por planta da videira/cv. Syrah, em ciclo de outono. Três Corações-MG, 2003

\begin{tabular}{lcccccc}
\hline Planta & $\begin{array}{c}\mathbf{N}^{\circ} \text { Gemas } \\
\text { na poda }\end{array}$ & $\begin{array}{c}\mathbf{N}^{\circ} \text { Ramos } \\
\text { Brotados }\end{array}$ & \% Brotação & $\mathbf{N}^{\circ}$ Cachos. pl $^{-1}$ & $\begin{array}{c}\text { Fertilidade do ramo } \\
\left(\mathbf{n}^{\mathbf{0}} \text { cachos.ramo-1) }\right.\end{array}$ & $\begin{array}{c}\text { Produção } \\
\left(\mathbf{k g g}^{-\mathbf{p l a n t a}} \mathbf{- 1}\right)\end{array}$ \\
\hline Média & 26,71 & 12,71 & 48,00 & 19,83 & 1,56 & 3,17 \\
\hline C.V. (\%) & 18,65 & 17,28 & 11,02 & 20,42 & 12,32 & 20,42 \\
\hline I.C. & 2,62 & 1,15 & 2,79 & 2,13 & 0,10 & 0,34 \\
\hline
\end{tabular}

\section{REFERÊNCIAS}

ALBUQUERQUE, T.C.S. Uva para exportação: aspectos técnicos da produção. Brasília: Embrapa-SPI, 1996. 53p.

ALLEWELDT, G. und RUHL, E. Untersuchungen zum Gaswechsel der RebeII. Einfluß langanhaltender Bodentrockenheit auf die Leistungsfähigkeit verschierdener Rebsorten. Vitis, Siebeldingen, v. 21, p. 313-324, 1982

CARBONNEAU, A. Observations sur vigne. Codification des données agronomiques. Vitis, Siebeldingen, v.5, n.2, p.9-13, 1981.

CASTRO, R. ; LOPES, C. ; CLIMACO P. ; CHAVES, M. M. Résultats écophysiologiques de la vigne au Portuga: Aspects hydriques. In : C. R. REUNION DU GESCO, 1993, Reims, France. p. 172-177.

CHAMPAGNOL, F. Elements de physiologie de la vigne et de viticulture generale. Saint-Gely-du-Fesc : Champagnol, 1984.351p.

CHAVES, M. M. Fotossíntese e repatição dos produtos de assimilação en V. vinifera L. 1986. 220f. Tese (Doutorado) - Universidade Técnica de Lisboa, Portugal, 1986.

DOWNTOWN, W.J.S. ; GRANT, W.J.R. ; LOVEYS, B.R. Diurnal changes in the photosynthesis of field-grown grape vines. New Phytologist, Cambridge, v. 105, p. 71-80, 1987.

DURING, $\mathrm{H} . \quad \mathrm{CO}_{2}$ assimilation and photorespiration of grapevines leaves : responses to lightand drought. Vitis, Siebeldingen, v. 27, p.199-208, 1988

DURING, H. Gas exchange of grapevines leaves as affected by soil factors. In : INTERNATIONAL SYMPOSIUM ON GRAPEVINE PHYSIOLOGI, 4., 1992, San Michel All'adige Italie. Proceedings...

ENTAV. Catalogue des variétés et clones de vigne cultivées en France. 
Le Grau du Roi: ENTAV, 1995.357p.

EPAMIG. Atlas climatológico do Estado de Minas Gerais. Belo Horizonte : EPAMIG, 1982.

GINESTAR, C. ; EASTHAM, J. ; GRAY, S.; ILAND, P. Use of sap-flow sensors to schedule vineyard irrigation. II. Efects of post-veraison water deficits on composition of shiraz grapes. American Journal of Enology and Viticulture, Davis, v.49, n. 4, p. 421-428, 1998.

GUERRA, C.C. Maturação da uva e condução da vinificação para a elaboração de vinhos finos. In: REGINA, M. de A. (Ed.). Viticultura e enologia: atualizando conceitos. Caldas: EPAMIG-FECD, 2002. 179-192p.

HUGLIN, P. Biologie et ecologie de la vigne. Paris: Payot-Lausane, 1986.372p

LEÃO, P.C.S.; MAIA, J.D.G. Aspectos culturais em viticultura tropical. Uvas de mesa. Informe Agropecuário, Belo Horizonte, v. 19, n.194, p. 34-39, 1998.

LEÃO, P.C.S. Uva de mesa produção: aspectos técnicos. Brasília: Embrapa Informação tecnológica, 2001. 128p. (Frutas do Brasil;13).

PIRES, R.C.M.; SAKAI, E.; BASSOI, L.H.; FUJIWARA, M.; Irrigação. In: POMMER, C. V. (Ed.). Uva: tecnologia de produção, pós-colheita, mercado. Porto Alegre: Cinco Continentes, 2003. p. 477-523.

SOUZA, C.M; REGINA, M. de A.; PEREIRA, G.E.; FREITAS, G.F. Indicação de cultivares de videira para o Sul de Minas Gerais. In: REGINA, M.de A. (Ed.). Viticultura e enologia: atualizando conceitos. Caldas: EPAMIG-FECD, 2002. p.277-286.

TONIETTO, J. O conceito de denominação de origem como agente promotor da qualidade dos vinhos In: REGINA, M. de. A. (Ed.). Viticultura e enologia: atualizando conceitos. Caldas: EPAMIGFECD, 2002. 151-163 p. 